\title{
Use of Prazosin for Pediatric PTSD-Associated Nightmares and Sleep Disturbances: A Retrospective Chart Review
}

\author{
Brooks R. Keeshin · Qian Ding - Angela P. Presson - Steven J. Berkowitz • \\ Jeffrey R. Strawn
}

Received: June 2, 2017 / Published online: July 28, 2017

(C) The Author(s) 2017. This article is an open access publication

\section{ABSTRACT}

Introduction: Youth exposed to trauma have an increased risk for developing posttraumatic stress disorder (PTSD) and associated sleep disturbances and nightmares. The alpha-1

Enhanced Content To view enhanced content for this article go to http://www.medengine.com/Redeem/ A3E8F0602EF51F68.

B. R. Keeshin $(\varangle)$. A. P. Presson

Department of Pediatrics, University of Utah, Salt

Lake City, UT, USA

e-mail: Brooks.Keeshin@hsc.utah.edu

B. R. Keeshin

Department of Psychiatry, University of Utah, Salt

Lake City, UT, USA

Q. Ding · A. P. Presson

Division of Epidemiology, Department of Internal Medicine, University of Utah, Salt Lake City, UT, USA

\section{S. J. Berkowitz}

Department of Psychiatry, Perelman School of

Medicine, University of Pennsylvania, Philadelphia, PA, USA

\section{J. R. Strawn}

Department of Psychiatry and Behavioral

Neuroscience, University of Cincinnati College of

Medicine, Cincinnati, OH, USA

\section{J. R. Strawn}

Division of Child and Adolescent Psychiatry, Department of Pediatrics, Cincinnati Children's Hospital Medical Center, Cincinnati, OH, USA antagonist prazosin reduces sleep disturbances and nightmares in adults with PTSD; however, its use in youth with PTSD has not been systematically evaluated. We retrospectively examined the tolerability and clinical outcomes associated with prazosin treatment in youth with PTSD-related nightmares and dysomnias.

Method: A retrospective chart review identified youth with PTSD $(N=40)$ treated with prazosin between 2014 and 2016 in a trauma clinic. We assessed the UCLA PTSD Reaction Index for Diagnostic and Statistical Manual of Mental Disorders, Fifth Edition scores (and sub-scores for intrusive, hyperarousal, avoidant and negative cognition/mood symptoms) and sleep scale, as well as adverse events and vital signs. Linear mixed effects models were utilized to evaluate the change in symptom severity, and vital signs were monitored throughout treatment.

Result: Follow-up data were available for 34 patients with PTSD (mean age $13.4 \pm 2.9$ years, $82 \%$ female), of whom $76 \%$ had a history of sexual abuse and $65 \%$ had at least one comorbid psychiatric disorder. The mean duration of prazosin treatment was $10.2 \pm 8.1$ (range 2-30) weeks, and the mean number of follow-up visits was $3 \pm 1.23$. Of these 34 patients, $79 \%$ received trauma-focused cognitive behavioral therapy. The dose range of prazosin was 1-15 mg at every bedtime $(0.02-0.3 \mathrm{mg} / \mathrm{kg})$, with $35 \%$ receiving $\geq 5 \mathrm{mg} /$ day. Treatment-emergent side effects were reported by $26 \% \quad(n=8)$ of patients, 
including dizziness (18\%), anxiety (9\%) and headaches $(6 \%)$. Prazosin treatment was associated with improved sleep and nightmares over time (pre-treatment $7.3 \pm 0.9$, post-treatment $3.1 \pm 2.4 ; p<0.001)$.

Conclusion: Prazosin was well-tolerated and associated with improvements in nightmares and sleep in youth with PTSD. Adverse events were consistent with the known side-effect profile of prazosin and included dizziness and nausea.

Keywords: Nightmares; Posttraumatic stress disorder; Prazosin; Sexual abuse; Sleep disturbances; Trauma

\section{INTRODUCTION}

Up to $80 \%$ of children will experience at least one potentially traumatic experience during childhood, and posttraumatic stress disorder (PTSD) is common among children and adolescents with a history of trauma [1]. PTSD-related nightmares and sleep disturbances in pediatric patients with PTSD may independently affect the severity and course of PTSD in youth [2]. Currently, trauma-focused psychotherapies represent the first line treatments for children with PTSD, with Trauma Focused Cognitive Behavioral Therapy (TF-CBT) the most studied of the trauma-based interventions [3]; however, treatment response varies [4, 5], and some intrusive symptoms may fail to improve with these trauma-focused psychotherapies. Moreover, there is little guidance for clinicians regarding the appropriate use of adjunctive pharmacotherapy in this population. To date, no placebo-controlled trials of selective serotonin reuptake inhibitors (SSRIs) in youth with PTSD have demonstrated their superiority to placebo [6, 7], and studies of antiadrenergics-which are commonly utilized in adults with PTSD-are limited to case reports [8-10] and open label trials [11].

The autonomic nervous system (ANS), a principal effector of stress response, has been implicated in the pathophysiology of PTSD [12] and may potentiate altered sleep architecture after trauma (e.g. including increased stage 1 sleep, decreased slow-wave sleep and increased activity in REM sleep) [13, 14]. Central norepinephrine concentrations are both elevated in adults with chronic PTSD and correlated with the severity of PTSD symptoms [15]. Changes in ANS function may also predict trauma-related psychopathology in children. Pediatric maltreatment victims have been found to have increased 24-h urinary catecholamine excretion $[16,17]$, and elevated plasma norepinephrine levels are present in children who subsequently develop PTSD within 6 months of a motor vehicle accident (MVA) compared to MVA victims who do not develop PTSD [18] over the same period. Additionally, salivary $\alpha$-amylase (sAA) concentrations, a marker of ANS activity, have been associated with PTSD symptoms in recently sexually abused girls and correlate with the severity of intrusive symptoms [19], including nightmares.

\section{Antiadrenergic Agents}

Given that research has consistently demonstrated increased noradrenergic tone in both adults [12] and youth with PTSD [19], several investigators have explored the efficacy of antiadrenergic agents for the prevention and treatment of pediatric PTSD. Propranolol is a centrally active antagonist of norepinephrine at the postsynaptic beta adrenoreceptor. It has been used off-label for the treatment of situational anxiety, and Famularo and colleagues demonstrated reductions in PTSD symptoms in an open label pilot study [20]. However, subsequent studies examining the use of propranolol among trauma-exposed youth have had negative results. In youth aged 10-18 years with MVA-related trauma, a randomized controlled trial (RCT) failed to detect differences between propranolol-treated youth and those who received placebo in terms of PTSD symptom severity or incidence of PTSD diagnosis at 6 weeks [21].

Alpha-2 $\left(\alpha_{2}\right)$ agonists (e.g. clonidine and guanfacine) are commonly utilized in the treatment of youth with attention-deficit/hyperactivity disorder (ADHD) [22] and are also utilized for pediatric patients with impulsive 
aggression and insomnia. These agents, agonists at the inhibitory pre-synaptic $\alpha_{2}$-adrenoreceptors, are prescribed to trauma-exposed children with severe trauma-related behavioral manifestations, including sleep disturbances [23]. Clonidine has been shown in open label trials to have the potential to attenuate hyperarousal, and in abused youth, clonidine decreases reenactment symptoms [24, 25]. Similarly, case reports of guanfacine use suggest improvement in nightmares in children with PTSD [26]. However, when guanfacine was examined in an open label trial of PTSD, although improvements were noted for reexperiencing and hyperarousal symptoms [11], most children with nightmares did not experience resolution of their nightmares while taking extended-release guanfacine [27].

In adults with PTSD, the efficacy of the $\alpha_{1}$-antagonist prazosin for the treatment of nightmares and dysomnia associated with PTSD is supported by multiple double-blind, placebo-controlled studies in both military and non-military populations [28-33]. Prazosin is the only $\alpha_{1}$-blocking agent at the postsynaptic $\alpha_{1}$-adrenoreceptor that blocks the effect of norepinephrine centrally when administered peripherally [34]. However, prazosin has not been systematically evaluated in the pediatric population, and a review of the pediatric literature identified fewer than five cases describing the potential efficacy and tolerability of prazosin in children and adolescents $[8,9]$. Thus, due to a lack of data, it is unclear whether prazosin is tolerated and associated with improvement in nightmares and sleep problems in children and adolescents with PTSD. With this in mind, we retrospectively evaluated the tolerability and clinical course of adjunctive prazosin in pediatric patients with PTSD who experienced significant PTSD-associated nightmares and sleep disturbances.

\section{METHODS}

\section{Participants}

This retrospective evaluation of prazosin in traumatized youth was approved by the
University of Utah and Intermountain Healthcare Institutional Review Boards. All procedures followed were in accordance with the ethical standards of the responsible committee on human experimentation (institutional and national) and with the Helsinki Declaration of 1964, as revised in 2013. All children were treated at a single academic hospital-based mental health center that specialized in pediatric trauma and were already receiving evidence-based psychotherapy at the time of referral for psychiatric consultation. As is the practice in the clinic, regardless of the modality [TF-CBT, dialectical behavior therapy (DBT), parent child interaction therapy (PCIT), eye movement desensitization and reprocessing (EMDR)], all families of children identified as having persistent nightmares were provided coping skills and sleep hygiene guidance as part of their psychotherapy to address their nightmares. Children were only referred for medication evaluation if there were no improvements in nightmares and sleep-related problems during psychotherapy. Of 40 children who were psychiatrically evaluated and in whom prazosin was prescribed, six were lost to follow-up and 34 had at least one follow-up visit after starting the medication.

Prazosin-treated patients were between the ages of 5-18 [mean age \pm standard deviation (SD) $13.4 \pm 2.9$ ] years and had experienced various forms of trauma, including sexual abuse (76\%), family violence (38\%) and bullying (18\%). Although all patients met the Diagnostic and Statistical Manual of Mental Disorders, Fifth Edition (DSM-5) criteria for PTSD at the time of evaluation, comorbidity was common, with $65 \%$ with a comorbid diagnosis, most commonly anxiety (50\%) and depressive disorders (32\%). Nearly one-half (41\%) of the children were treated with an SSRI and 6\% were treated with a stimulant at some point during their use of prazosin.

Consensus guidelines suggest dose titration of prazosin at $1 \mathrm{mg} /$ week until sufficient improvement in sleep and/or reduction in nightmares is observed [35]. Prior to the initiation of prazosin treatment, families were routinely asked about the child's past medical history and the current state of symptoms and 
the family history were reviewed, with special attention paid to cardiovascular symptoms and risk. In the present sample, prazosin was initiated at $1 \mathrm{mg}$ at bedtime (QHS) in all patients to decease the risk of first dose orthostatic hypotension-related syncope [36]. However, we found that patients tolerated titration from 1 to $2 \mathrm{mg}$ QHS following three consecutive doses of $1 \mathrm{mg}$ QHS. If nightmares failed to respond to prazosin at $2 \mathrm{mg}$ after three additional nights, prazosin was generally titrated to $3 \mathrm{mg}$ QHS. Most patients had their first follow-up visit 2 weeks after the initiation of prazosin, and for those who would eventually need a higher dose, they returned to clinic having taken $3 \mathrm{mg}$ at night for 1 week, providing sufficient data were available to determine an appropriate increase in dose if necessary. The final prazosin dosage ranged from 1 to $15 \mathrm{mg}$ in a single dose [administered QHS, $0.02-0.3 \mathrm{mg} / \mathrm{kg}$ body weight (BW)], with $35 \%$ of patients receiving $\geq 5 \mathrm{mg} / \mathrm{kg}$ BW and $24 \%$ of patients receiving $\geq 0.1 \mathrm{mg} / \mathrm{kg}$ BW. Prazosin was generally discontinued around the time that the evidence-based trauma therapy was terminated.

\section{Clinical Measurements}

As part of standard clinical practice, all patients were administered the UCLA PTSD reaction index (UCLA PTSD RI) for DSM-5 [37] prior to starting prazosin and at each follow-up visit. Additionally, most adolescents completed the Adolescent Dissociative Experiences Scale (ADES) [38] at the time of the initial visit to characterize dissociative symptoms. As part of routine clinical care, vital signs were obtained at the initial and each subsequent visit, and the Clinical Global Impressions of Improvement (CGI-I) scale [39] was documented at each visit to indicate clinical response from baseline.

The UCLA PTSD RI version for DSM-5 is a 31-item measure that captures the presence and frequency of intrusive, avoidant, negative cognition/mood, hyperarousal and dissociative symptoms in PTSD. The DSM-IV version has been validated in several studies [40, 41], and the DSM-5 version is currently undergoing validation. For our clinical purposes, we developed a unique sleep subscale of the UCLA PTSD RI to monitor sleep problems (questions 10 and 21 from the UCLA PTSD RI) with a possible score range of 0 to 8 .

The ADES is a 30-item self-report measure that assesses dissociative symptoms. For each question, symptom frequency is rated on a scale of 0 to 10 , with 10 signifying that the symptom occurs "all the time." Prior studies have demonstrated that scores of $\geq 3.7$ suggest clinically significant dissociation [38].

For youth with comorbid depression, the diagnosis was made based on results of the Quick Inventory of Depression Symptomatology (QIDS) [42] and clinical interview. For comorbid anxiety disorders, the diagnosis was made based on the Screen for Child Anxiety Related Disorders (SCARED) [43] and clinical interview.

\section{Analytic Strategy}

Continuous variables were summarized by the mean $\pm \mathrm{SD}$, median with interquartile range and range; categorical variables were summarized as count with the percentage. Linear mixed effects models were used to compare each outcome variable with time (months) as the fixed effect, including a random effect for each subject to account for correlation among repeat measures within subjects. The coefficient of time and its 95\% confidence interval and $p$ value were reported for each model. Statistical analyses were conducted in $\mathrm{R}$ (version 3.3.1; $\mathrm{R}$ Foundation for Statistical Computing, Vienna, Austria) using two-tailed tests, and findings were considered to be statistically significant at $p \leq 0.05$ level.

\section{RESULTS}

\section{Demographic and Clinical Characteristics of the Patients}

Most patients were female, and most patients were treated with TF-CBT (79\%). Symptom severity was high at the beginning of treatment, and $35 \%$ of patients $(n=12)$ reported clinically 
significant dissociation. Additional demographic and clinical variables are shown in Table 1.

\section{Symptom Changes During Treatment}

Prazosin treatment was associated with significant improvement in PTSD symptoms, as assessed with the UCLA RI (baseline $51.7 \pm 10.4$; endpoint $35.1 \pm 14.5 ; p<0.0001$ ). The sleep subscale (combination of questions 10 and 21 from the UCLA PTSD RI) showed significant improvement (baseline $7.32 \pm 0.94$; endpoint $3.09 \pm 2.40 ; \quad p<0.0001)$. Similar improvements were noted for PTSD symptom clusters, including intrusive (baseline $13.7 \pm 3.5$; endpoint $8.5 \pm 4.4 ; \quad p<0.0001)$, avoidance (baseline $6.0 \pm 2.0$; endpoint $4.5 \pm 2.0 ; \quad p=0.002)$, negative or decreased cognition and mood (baseline $16.7 \pm 4.6$; endpoint $12.8 \pm 5.3 ; \quad p<0.0001)$ and arousal symptoms (baseline $15.3 \pm 3.3$; endpoint $9.8 \pm 4.7 ; p<0.0001$ ) symptoms (Table 2 ). Of the 34 patients enrolled in the study, 35\% $(n=12)$ were treated with $\geq 5 \mathrm{mg}$ (range 5-15 mg administered orally QHS) and 24\% were treated with $>0.1 \quad(0.1-0.3) \quad \mathrm{mg} / \mathrm{kg}$ BW (Fig. 1). No statistically significant differences were noted between patients treated with a low dose $(<5 \mathrm{mg} /$ night or $<0.1 \mathrm{mg} / \mathrm{kg} \quad \mathrm{BW} /$ night $)$ and high dose ( $\geq 5 \mathrm{mg} /$ night or $\geq 0.1 \mathrm{mg} / \mathrm{kg} \mathrm{BW} /$ night) prazosin in terms of baseline symptom severity, age or sex.

\section{Adverse Events}

The side effects reported by the 34 patients while taking prazosin are shown in Table 1 . Of note, although one-quarter of patients noted side effects, only four (12\%) discontinued prazosin due to side effects. Reported side effects included dizziness, anxiety and headaches. Blood pressure, heart rate and weight were closely monitored during prazosin treatment (Table 2). With the exception of a return of nightmares and sleep problems in several children who stopped taking prazosin while still symptomatic for PTSD, no adverse events were
Table 1 The pediatric patients with posttraumatic stress disorder $(N=34)$ reviewed in this study who were treated with prazosin and attended at least one follow-up visit

\begin{tabular}{|c|c|}
\hline Patient demographic and clinical variables & Values \\
\hline \multicolumn{2}{|l|}{ Age at intake (years) } \\
\hline Mean (SD) & $13.38(2.89)$ \\
\hline Range & $5-18$ \\
\hline Female gender, $n(\%)$ & $28(82.35)$ \\
\hline \multicolumn{2}{|l|}{ Race/ethnicity, $n$ (\%) } \\
\hline African American & $3(8.82)$ \\
\hline Caucasian & $22(64.71)$ \\
\hline Latino/a & $7(20.59)$ \\
\hline Native American & $2(5.88)$ \\
\hline \multicolumn{2}{|l|}{ Primary trauma $n(\%)$} \\
\hline Sexual abuse, & $26(76.47)$ \\
\hline Family violence & $13(38.24)$ \\
\hline Bullying & $6(17.65)$ \\
\hline Vicarious traumatic death & $5(14.71)$ \\
\hline Dissociation mean score $(\mathrm{SD})$ & $3.96(1.97)$ \\
\hline Comorbid diagnosis, $n(\%)$ & $22(64.71)$ \\
\hline Depressive disorder & $11(32.35)$ \\
\hline Anxiety disorder & $17(50)$ \\
\hline Attention-deficit/hyperactivity disorder (ADHD) & $3(8.82)$ \\
\hline \multicolumn{2}{|l|}{ Primary psychotherapy type, $n(\%)$} \\
\hline Dialectical behavior therapy (DBT) & $6(17.65)$ \\
\hline $\begin{array}{l}\text { Eye movement desensitization and reprocessing } \\
\text { (EMDR) }\end{array}$ & $1(2.94)$ \\
\hline $\begin{array}{l}\text { Trauma-Focused Cognitive Behavioral Therapy } \\
\text { (TF-CBT) }\end{array}$ & $27(79.41)$ \\
\hline \multicolumn{2}{|l|}{ Psychotropic medication, $n(\%)$} \\
\hline Selective serotonic reuptake inhibitor (SSRI) & $14(41.18)$ \\
\hline Stimulant & $2(5.88)$ \\
\hline \multicolumn{2}{|l|}{ Side effects reported during treatment } \\
\hline Side effects, $n(\%)$ & $8(23.53)$ \\
\hline Dizziness & $6(17.65)$ \\
\hline Anxiety & $3(8.82)$ \\
\hline Headache & $2(5.88)$ \\
\hline \multicolumn{2}{|l|}{ Follow-up time (months) } \\
\hline Mean (SD) & $2.34(1.87)$ \\
\hline Median (IQR) & $\begin{array}{l}1.70(1.00 \\
2.80)\end{array}$ \\
\hline \multicolumn{2}{|l|}{ Number of visits, $n$ (\%) } \\
\hline 2 & $14(41.18)$ \\
\hline 3 & $11(32.35)$ \\
\hline $4+$ & $9(26.47)$ \\
\hline
\end{tabular}

SD, Standard deviation; IQR interquartile range 
Table 2 Posttraumatic stress disorder symptoms and vital signs at baseline and last time point, and change-over time

\begin{tabular}{lllll}
\hline Variable & Baseline, mean $(\mathbf{S D})$ & Last time point, mean $(\mathbf{S D})$ & Time estimate $(95 \%$ CI) & Significance \\
\hline Sleep score (range 0-8) & $7.32(0.94)$ & $3.09(2.40)$ & $-0.939(-1.219,-0.659)$ & $<0.0001^{*}$ \\
UCLA score & $51.65(10.42)$ & $35.06(14.52)$ & $-4.5(-5.821,-3.179)$ & $<0.0001^{*}$ \\
Intrusive & $13.65(3.52)$ & $8.53(4.41)$ & $-1.241(-1.691,-0.791)$ & $<0.0001^{*}$ \\
Avoidance & $6.03(1.95)$ & $4.53(1.95)$ & $-0.35(-0.565,-0.134)$ & $0.0019^{*}$ \\
Negative mood & $16.71(4.61)$ & $12.75(5.27)$ & $-1.217(-1.682,-0.751)$ & $<0.0001^{*}$ \\
Arousal & $15.26(3.33)$ & $9.78(4.72)$ & $-1.62(-2.062,-1.178)$ & $<0.0001^{*}$ \\
Weight & $54.51(17.16)$ & $55.80(17.32)$ & $0.331(0.15,0.512)$ & $0.0005^{*}$ \\
Systolic blood pressure & $104.64(8.88)$ & $106.83(11.81)$ & $0.103(-0.901,1.106)$ & 0.84 \\
Diastolic blood pressure & $61.30(8.15)$ & $62.63(8.30)$ & $0.565(-0.269,1.4)$ & 0.18 \\
Heart rate & $77.58(13.03)$ & $81.83(10.70)$ & $1.212(-0.117,2.541)$ & 0.07 \\
\hline
\end{tabular}

* Significant difference between baseline and last time point at $p \leq 0.05$

CI, Confidence interval

noted with either planned or unplanned discontinuation of prazosin.

\section{DISCUSSION}

To our knowledge, our study is the largest evaluation of prazosin for the treatment of nightmares and sleep disturbances in pediatric patients with PTSD. Herein, we retrospectively observed that prazosin treatment was associated with a clinically significant decrease in nightmares and sleep problems and that the medication was well tolerated. Furthermore, these data significantly extend the previously reported dose ranges utilized in pediatric patients with PTSD. However, several findings warrant additional discussion.

In all patients, prazosin was initiated at $1 \mathrm{mg}$ nightly and titrated, gradually, to $2-3 \mathrm{mg}$ QHS depending on clinical response over the first 2 weeks. Clinical response, as measured by the family subjective report and the sleep subscale on the UCLA PTSD RI, guided further titration. Those patients who required a higher final dose of prazosin had exhibited delayed treatment responses compared to those whose final prazosin dose was $<5 \mathrm{mg} /$ night or $<0.1 \mathrm{mg} / \mathrm{kg} \mathrm{BW/}$ night (Fig. 1). This process of incremental increase and reassessment likely accounts for the tolerability of doses higher than those reported in the literature as well as the delay in response to treatment among patients treated $\geq 5 \mathrm{mg}$ or $\geq 0.1 \mathrm{mg} / \mathrm{kg}$ BW of prazosin.

The adverse events reported by the patients are consistent with the known side-effect profile of prazosin and included dizziness and nausea. Although nearly one-quarter of patients reported side effects, only four patients (12\%) discontinued prazosin secondary to these side effects. Moreover, even if it were to be assumed that all patients lost to follow-up discontinued treatment as a result of side effects, this proportion would still be $25 \%$ discontinuing (10 of 40 possible patients). Of potential clinical importance, two of the four patients who discontinued treatment did so as a result of increased nighttime anxiety after taking the prazosin. Both patients reported similar experiences of having significantly decreased hypervigilance and a subsequent feeling of being unable to keep themselves safe from potential harm at night after taking low doses of prazosin (1-2 mg QHS). Both patients had severe, chronic PTSD with dissociation, histories of chronic sexual abuse and significant comorbid anxiety disorders. Neither patient felt their trauma symptoms were pathologic, but rather 


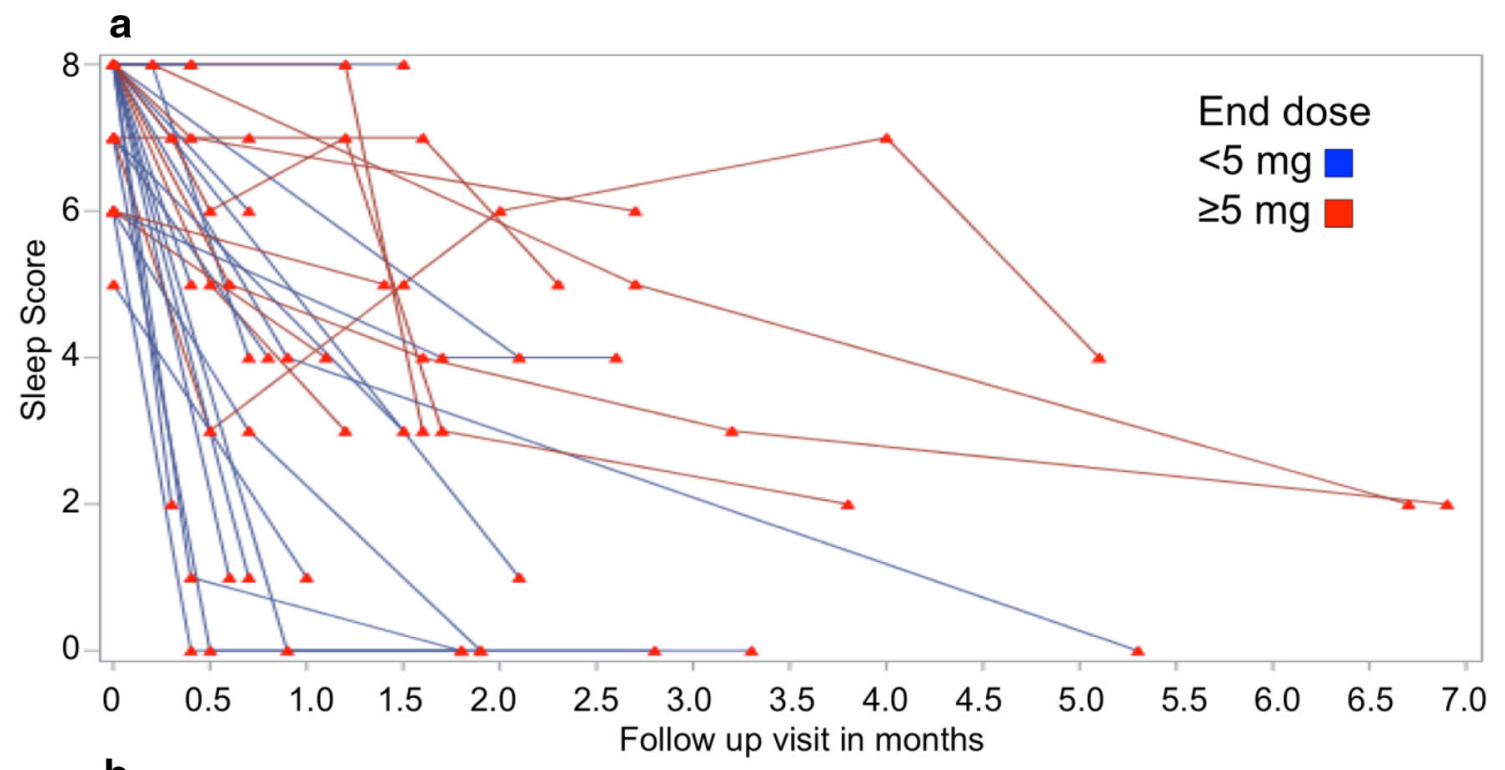

Fig. 1 Plots of sleep scores in prazosin-treated patients. Each line represents the reported sleep symptom score (range 0-8) for individual patients. Decreases represent

saw their hypervigilance as an effective means to keep themselves safe from future abuse. In both cases, the patients were successfully treated with combination therapy of trauma focused therapy and adjuvant SSRI treatment for anxiety.

Some patients who discontinued prazosin prematurely while continuing to experience PTSD symptoms reported a return of symptomatic improvement. a Rate of improvement based on final absolute dose, $\mathbf{b}$ categorization based on final dose in $\mathrm{mg} / \mathrm{kg}$ body weight

nightmares and sleep disturbances. No patients reported symptoms consistent with rebound hypertension (e.g. headache, nausea, anxiety) or noted other side effects when prazosin was discontinued. In normotensive volunteers, prazosin does not appear to lower blood pressure compared to clonidine [44]. $\alpha_{2}$-Agonists, such as clonidine and guanfacine [45], have been associated with rebound hypertension when 
abruptly discontinued following chronic use, likely related to suppressed sympathetic tone [46]. However, this appears to be a phenomenon specific to $\alpha_{2}$-agonists and is not commonly observed in $\alpha_{1}$-antagonists such as prazosin. Our clinical experience reinforces the current observation that prazosin discontinuation was well tolerated without the need for gradual decreases in dose prior to discontinuation.

Within this sample, patients treated with prazosin appeared to be divided into two groups, low dose responders and high dose responders. Current expert consensus indicates that appropriate dosing for prazosin ranges from 1 to $4 \mathrm{mg}$ orally QHS for youth. However, in our sample, $35 \%$ were treated with $\geq 5 \mathrm{mg}$ QHS, including six patients treated with $\geq 10 \mathrm{mg}$. In general, we found that youth who were sensitive to the medication (including most patients with reported side effects) were receiving doses of $\leq 4 \mathrm{mg}$ when the side effects were reported, whereas those youth who required higher doses were less likely to report any side effects when the medication was adjusted above $4 \mathrm{mg}$. The low rate of overall side effects among our 34 patients on prazosin is understandable given the time of administration (30-60 min before bedtime) as well as the general good cardiovascular health found among pediatric populations compared to adult populations.

Cognitive behavioral therapies, such as TF-CBT, are first-line treatments for traumatized children and adolescents [3], yet not all children benefit from such interventions, and the impact of these therapies on trauma-specific sleep disturbances is not well established [2]. Pharmacologically, adrenergic modulating agents have demonstrated efficacy in reducing or ameliorating nighttime disturbances in adults with PTSD. Specifically, prazosin has demonstrated efficacy in the reduction of nighttime-related symptoms in multiple RCTs in adults [47] and in case reports in children [8]. Other antiadrenergic agents commonly used in the pediatric population, such as guanfacine and clonidine, have demonstrated mixed results in the treatment of PTSD [3], although it remains possible that the utility of $\alpha_{2}$-agonists may be more significant on pediatric PTSD that is comorbid with ADHD [11]. Future research that incorporates ANS biomarkers (e.g. sAA) may improve our understanding of the underlying pathophysiology of PTSD and treatment response and possibly lead to the identification of children who would benefit from specific psychopharmacologic treatments.

While our chart review is the largest evaluation of prazosin in pediatric patients with nightmares and sleep disturbances associated with PTSD, several important limitations warrant discussion. Given the retrospective nature of this evaluation, a control group is lacking, and some children included in the review may have experienced symptomatic improvement as a result of supportive interventions administered through the trauma clinic. Furthermore, all patients received trauma focused psychotherapy, and prazosin treatment was adjunctive and followed the failure of behavioral interventions for sleep, likely excluding some patients whose nightmare symptoms would have resolved with psychotherapeutic intervention alone. Additionally, at least four patients discontinued prazosin for 2-8 weeks, with recrudescence nightmares, which abated upon reinitiating prazosin therapy. However, in the absence of a randomized, placebo-controlled trial, the efficacy of adjunctive prazosin in reducing nightmares over time cannot be conclusively established. Weight increased over time at a rate consistent with normal growth in youth; however, future controlled studies should closely monitor weight change in youth while on prazosin. Additionally, although findings regarding vital signs and reported side effects add to the known safety and tolerability of prazosin in normotensive youth with PTSD, the sample is small and it is unlikely that rare but potentially significant side effects that could result from administering a medication with cardiovascular properties to a normotensive population would have been detected. Nonetheless, the generally healthy cardiovascular systems of children and adolescents with normally functioning compensatory mechanisms likely explain the minimal blood pressure-related difficulties in long-term trials of antiadrenergic agents in youth $[48,49]$. 


\section{CONCLUSION}

Prazosin may be a helpful adjunctive treatment for nightmares and sleep disturbances associated with PTSD in pediatric patients. Our data support previous findings that prazosin is well tolerated and associated with significant decreases in nightmare frequency and severity and sleep problems in youth with PTSD who are receiving evidence-based trauma focused psychotherapies. The use of prazosin, an antiadrenergic agent, may represent an intervention that specifically targets the pathophysiology of PTSD in that autonomic hyperactivity in pediatric patients with PTSD has been consistently observed in youth for nearly two decades. Importantly, the extant evidence base for antiadrenergic medications in the treatment of PTSD-associated sleep problems, including our findings, should be applied with caution in the pediatric population, particularly in light of the relatively small samples in these studies and the lack of a control group in the present study. Randomized, prospective, controlled studies of prazosin in the treatment of nightmares in children with PTSD are urgently needed.

\section{ACKNOWLEDGMENTS}

This investigation was supported by a grant from the University of Utah Study Design and Biostatistics Center, with funding in part from the National Center for Research Resources and the National Center for Advancing Translational Sciences, National Institutes of Health, through Grant 5UL1TR001067-02 (formerly 8UL1TR000105 and UL1RR025764). The article processing charges were supported by a grant from the Substance Abuse and Mental Health Services Administration, 1U79SM080000. All named authors meet the International Committee of Medical Journal Editors (ICMJE) criteria for authorship for this manuscript, take responsibility for the integrity of the work as a whole and have given final approval for the version to be published.
Disclosures. Dr. Keeshin has received support from the Substance Abuse and Mental Health Services Administration. Dr. Berkowitz has received support from Substance Abuse and Mental Health Services and Patient-Centered Outcomes Research Institute. Dr. Strawn has received research support from the National Institute of Mental Health and the National Institute of Environmental and Health Science, Allergan, Edgemont Pharmaceuticals, Lundbeck, Neuronetics and Shire and has received material support from Genesight/Assurex. Ms. Ding and Dr. Presson have nothing to disclose.

Compliance with Ethics Guidelines. This retrospective evaluation of prazosin in traumatized youth was approved by the University of Utah and Intermountain Healthcare Institutional Review Boards. All procedures followed were in accordance with the ethical standards of the responsible committee on human experimentation (institutional and national) and with the Helsinki Declaration of 1964, as revised in 2013.

Data Availability. The datasets during and/ or analyzed during the current study are available from the corresponding author on reasonable request.

Open Access. This article is distributed under the terms of the Creative Commons Attribution-NonCommercial 4.0 International License (http://creativecommons.org/licenses/ by-nc/4.0/), which permits any noncommercial use, distribution, and reproduction in any medium, provided you give appropriate credit to the original author(s) and the source, provide a link to the Creative Commons license, and indicate if changes were made.

\section{REFERENCES}

1. Scheeringa MS, Zeanah $\mathrm{CH}$, Cohen JA. PTSD in children and adolescents: toward an empirically based algorithma. Depress Anxiety. 2011;28:770-82.

2. Kovachy B, O'Hara R, Hawkins N, Gershon A, Primeau MM, Madej J, et al. Sleep disturbance in 
pediatric PTSD: current findings and future directions. J Clin Sleep Med. 2013;9:501-10.

3. Keeshin BR, Strawn JR. Psychological and pharmacologic treatment of youth with posttraumatic stress disorder: an evidence-based review. Child Adolesc Psychiatr Clin N Am. 2014;23:399-411.

4. Morina N, Koerssen R, Pollet TV. Interventions for children and adolescents with posttraumatic stress disorder: a meta-analysis of comparative outcome studies. Clin Psychol Rev. 2016;47:41-54.

5. Silverman WK, Ortiz CD, Viswesvaran C, Burns BJ, Kolko DJ, Putnam FW, et al. Evidence-based psychosocial treatments for children and adolescents exposed to traumatic events. J Clin Child Adolesc Psychol. 2008;37:156-83.

6. Cohen JA, Mannarino AP, Perel JM, Staron V. A pilot randomized controlled trial of combined trauma-focused CBT and sertraline for childhood PTSD symptoms. J Am Acad Child Adolesc Psychiatry. 2007;46:811-9.

7. Robb AS, Cueva JE, Sporn J, Yang R, Vanderburg DG. Sertraline treatment of children and adolescents with posttraumatic stress disorder: a double-blind, placebo-controlled trial. J Child Adolesc Psychopharmacol. 2010;20:463-71.

8. Strawn JR, Keeshin BR. Successful treatment of posttraumatic stress disorder with prazosin in a young child. Ann Pharmacother. 2011;45:1590-1.

9. Strawn JR, Delbello MP, Geracioti TD. Prazosin treatment of an adolescent with posttraumatic stress disorder. J Child Adolesc Psychopharmacol. 2009;19:599-600.

10. Brkanac Z, Pastor JF, Storck M. Prazosin in PTSD. J Am Acad Child Adolesc Psychiatry. 2003;42:384-5

11. Connor DF, Grasso DJ, Slivinsky MD, Pearson GS, Banga A. An open-label study of guanfacine extended release for traumatic stress related symptoms in children and adolescents. J Child Adolesc Psychopharmacol. 2013;23:244-51.

12. Strawn JR, Geracioti TD. Noradrenergic dysfunction and the psychopharmacology of posttraumatic stress disorder. Depress Anxiety. 2008;25:260-71.

13. Germain A, Buysse DJ, Nofzinger E. Sleep-specific mechanisms underlying posttraumatic stress disorder: integrative review and neurobiological hypotheses. Sleep Med Rev. 2008;12:185-95.

14. Harvey AG, Jones C, Schmidt DA. Sleep and posttraumatic stress disorder: a review. Clin Psychol Rev. 2003;23:377-407.
15. Geracioti TD, Baker DG, Ekhator NN, West SA, Hill $\mathrm{KK}$, Bruce $\mathrm{AB}$, et al. CSF norepinephrine concentrations in posttraumatic stress disorder. Am J Psychiatry. 2001;158:1227-30.

16. De Bellis MD, Lefter L, Trickett PK, Putnam FW. Urinary catecholamine excretion in sexually abused girls. J Am Acad Child Adolesc Psychiatry. 1994;33:320-7.

17. De Bellis MD, Baum AS, Birmaher B, Keshavan MS, Eccard CH, Boring AM, et al. A. E. Bennett Research Award. Developmental traumatology. Part I: biological stress systems. Biol Psychiatry. 1999;45:1259-70.

18. Pervanidou P, Chrousos GP. Post-traumatic Stress Disorder in children and adolescents: from Sigmund Freud's 'trauma' to psychopathology and the (Dys)metabolic syndrome. Horm Metab Res. 2007;39:413-9.

19. Keeshin BR, Strawn JR, Out D, Granger DA, Putnam FW. Elevated salivary alpha amylase in adolescent sexual abuse survivors with posttraumatic stress disorder symptoms. J Child Adolesc Psychopharmacol. 2015;25:344-50.

20. Famularo R, Kinscherff R, Fenton T. Propranolol treatment for childhood posttraumatic stress disorder, acute type. A pilot study. Am J Dis Child. 1988;142:1244-7.

21. Nugent NR, Christopher NC, Crow JP, Browne L, Ostrowski S, Delahanty DL. The efficacy of early propranolol administration at reducing PTSD symptoms in pediatric injury patients: a pilot study. J Trauma Stress. 2010;23:282-7.

22. Bloch MH, Panza KE, Landeros-Weisenberger A, Leckman JF. Meta-analysis: treatment of attention-deficit/hyperactivity disorder in children with comorbid tic disorders. J Am Acad Child Adolesc Psychiatry. 2009;48:884-93.

23. Donnelly CL. Pharmacologic treatment approaches for children and adolescents with posttraumatic stress disorder. Child Adolesc Psychiatr Clin N Am. 2003;12:251-69.

24. Harmon RJ, Riggs PD. Clonidine for posttraumatic stress disorder in preschool children. J Am Acad Child Adolesc Psychiatry. 1996;35:1247-9.

25. Porter DM, Bell CC. The use of clonidine in post-traumatic stress disorder. J Natl Med Assoc. 1999;91:475-7.

26. Horrigan JP, Barnhill LJ. The suppression of nightmares with guanfacine. J Clin Psychiatry. 1996;57:371. 
27. Sallee FR, Lyne A, Wigal T, McGough JJ. Long-term safety and efficacy of guanfacine extended release in children and adolescents with attention-deficit/ hyperactivity disorder. J Child Adolesc Psychopharmacol. 2009;19:215-26.

28. Raskind MA, Peskind ER, Hoff DJ, Hart KL, Holmes HA, Warren D, et al. A parallel group placebo controlled study of prazosin for trauma nightmares and sleep disturbance in combat veterans with post-traumatic stress disorder. Biol Psychiatry. 2007;61:928-34.

29. Raskind MA, Thompson C, Petrie EC, Dobie DJ, Rein RJ, Hoff DJ, et al. Prazosin reduces nightmares in combat veterans with posttraumatic stress disorder. J Clin Psychiatry. 2002;63:565-8.

30. Byers MG, Allison KM, Wendel CS, Lee JK. Prazosin versus quetiapine for nighttime posttraumatic stress disorder symptoms in veterans: an assessment of long-term comparative effectiveness and safety. J Clin Psychopharmacol. 2010;30:225-9.

31. Raskind MA, Peskind ER, Kanter ED, Petrie EC, Radant A, Thompson CE, et al. Reduction of nightmares and other PTSD symptoms in combat veterans by prazosin: a placebo-controlled study. Am J Psychiatry. 2003;160:371-3.

32. Boynton L, Bentley J, Strachan E, Barbato A, Raskind M. Preliminary findings concerning the use of prazosin for the treatment of posttraumatic nightmares in a refugee population. J Psychiatr Pract. 2009;15:454-9.

33. George KC, Kebejian L, Ruth LJ, Miller CWT, Himelhoch S. Meta-analysis of the efficacy and safety of prazosin versus placebo for the treatment of nightmares and sleep disturbances in adults with posttraumatic stress disorder. J Trauma Dissociation. 2016;17:494-510.

34. Menkes DB, Baraban JM, Aghajanian GK. Prazosin selectively antagonizes neuronal responses mediated by alpha1-adrenoceptors in brain. Naunyn Schmied Arch Pharmacol. 1981;317:273-5.

35. Strawn JR, Keeshin BR, Delbello MP, Geracioti TD, Putnam FW. Psychopharmacologic treatment of posttraumatic stress disorder in children and adolescents: a review. J Clin Psychiatry. 2010;71:932-41.

36. Hasford J, Bussmann WD, Delius W, Koepcke W, Lehmann K, Weber E. First dose hypotension with enalapril and prazosin in congestive heart failure. Int J Cardiol. 1991;31:287-93.

37. Pynoos RS, Steinberg AM. UCLA PTSD Reaction Index: DSM-5 Version. Los Angeles, CA, USA: National Center for Child Traumatic Stress; 2014

38. Armstrong JG, Putnam FW, Carlson EB, Libero DZ, Smith SR. Development and validation of a measure of adolescent dissociation: the adolescent dissociative experiences scale. J Nerv Ment Dis. 1997;185:491-7.

39. Guy W, editor. ECDEU Assessment Manual for Psychopharmacology. Rockville, MD: National Institute of Mental Health; 1976. pp. 76-338

40. Steinberg AM, Brymer MJ, Kim S, Briggs EC, Ippen CG, Ostrowski SA, et al. Psychometric properties of the UCLA PTSD reaction index: part I. J Trauma Stress. 2013;26:1-9.

41. Elhai JD, Layne CM, Steinberg AM, Brymer MJ, Briggs EC, Ostrowski SA, et al. Psychometric properties of the UCLA PTSD reaction index. Part II: investigating factor structure findings in a national clinic-referred youth sample. J Trauma Stress. 2013;26:10-8.

42. Rush AJ, Trivedi MH, Ibrahim HM, Carmody TJ, Arnow B, Klein DN, et al. The 16-Item quick inventory of depressive symptomatology (QIDS), clinician rating (QIDS-C), and self-report (QIDS-SR): a psychometric evaluation in patients with chronic major depression. Biol Psychiatry. 2003;54:573-83.

43. Birmaher B, Khetarpal S, Brent D, Cully M, Balach L, Kaufman J, et al. The screen for child anxiety related emotional disorders (SCARED): scale construction and psychometric characteristics. J Am Acad Child Adolesc Psychiatry. 1997;36:545-53.

44. Moore N, Fresel J, Joannidès R, Compagnon $\mathrm{P}$, Thuillez C. A comparison of the hemodynamic effects of urapidil, prazosin, and clonidine in healthy volunteers. Blood Press Suppl. 1994;4:7-12.

45. Reid JL, Campbell BC, Hamilton CA. Withdrawal reactions following cessation of central alpha-adrenergic receptor agonists. Hypertension. 1984;6:II71-5.

46. Campbell BC, Reid JL. Regimen for the control of blood pressure and symptoms during clonidine withdrawal. Int J Clin Pharmacol Res. 1985;5:215-22.

47. Kung S, Espinel Z, Lapid MI. Treatment of nightmares with Prazosin: a systematic review. Mayo Clin Proc. 2012;87:890-900.

48. Biederman J, Melmed RD, Patel A, McBurnett K, Donahue J, Lyne A. Long-term, open-label extension study of guanfacine extended release in children and adolescents with ADHD. CNS Spectr. 2008;13:1047-55.

49. Hirota T, Schwartz S, Correll CU. Alpha-2 agonists for attention-deficit/hyperactivity disorder in youth: a systematic review and meta-analysis of monotherapy and add-on trials to stimulant therapy. J Am Acad Child Adolesc Psychiatry. 2014;53:153-73. 